\title{
Oficina de fotos: um método participativo de análise do trabalho
}

\section{A Photo Workshop: A Participatory Method of Job Analysis}

Recibido: marzo 4 de 2013 | Revisado: julio 30 de 2013 | Aceptado: septiembre 15 de 2013

\author{
Claudia Osorio da Silva** \\ Universidade Federal Fluminense, Brasil \\ Maria Elizabeth Barros De BARros *** \\ Universidade Federal do Rio de Janeiro, Brasil
}

Doi: 10.11144/Javeriana.UPSY12-4.ofmp

Para citar este artículo: Osorio, da Silva, C., \& Barros, M. E. B., de. (2013). Oficina de fotos: um método participativo de análise do trabalho. Universitas Psychologica, 12(4), 1325-1334. Doi: 10.11144/ Javeriana.UPSY12-4.ofmp

Psicóloga, doutora em Saúde Pública, docente na Universidade Federal Fluminense.

** Psicóloga, doutora em Educação, docente na Universidade Federal do Rio de Janeiro.

\begin{abstract}
RES U M O
$\mathrm{O}$ artigo apresenta uma experiência de oficina de fotos desenvolvida em um hospital público no Brasil. Nesta, a proposta metodológica da clínica da atividade lança mão do recurso da fotografia digital, fazendo com que o processo de produção da fotografia se dê também como processo de análise da atividade. No momento seguinte as fotos produzidas são postas em debate, em um diálogo sobre a atividade que se desenvolve em torno dos modos coletivos de fazer e suas controvérsias. Ao apresentar essa experiência, busca-se desenvolver uma ferramenta de análise do trabalho que visa explorar e desestabilizar os modos instituídos de trabalhar e potencializar forças instituintes que compõem uma determinada situação, engendrando outras que viabilizam a ampliação do poder de agir dos trabalhadores.

Palavras-chave autores

Trabalho, atividade, subjetividade, metodologia, método.

Palavras-chave descriptores

Psicologia social, Trabalho, Brasil.
\end{abstract}

\section{A B S T R A C T}

This paper presents an experience of a Photo Workshop, developed in a public hospital in Brazil. Then, the methodological proposal of the Clinic of Activity makes use of the resource of digital photography, making the photography production process a process of the analysis of the activity as well. The next step was to take the pictures produced and put them in discussion, in a dialogue about the activity that is developed around the collective modes used in the process and their controversies. In presenting this experience, we seek to develop a tool for analysing the work which exploit and destabilize the established modes of working and also enhance instituting forces that make up a given situation, engendering other ones that enable the expansion of workers' action power.

Key words authors

Work activity, subjectivity, methodology, method.

Key words plus

Social Psychology, Work, Brazil. 


\section{Introdução}

A proposta de usar a fotografia como mediadora na análise do trabalho surgiu da parceria entre uma universidade federal ${ }^{1}$ com um hospital da rede do Sistema Único de Saúde (SUS), situados na cidade do Rio de Janeiro, com a inserção de estagiários de psicologia na Comissão de Saúde do Trabalhador do hospital no período de 1996 a 2006 (Osorio da Silva \& Oliveira, 1999). Foram anos fecundos, em que a convivência com os membros dessa comissão e com os demais profissionais do hospital favoreceram a experimentação de caminhos de pesquisa e intervenção em saúde do trabalhador da área da saúde. É de uma dessas experimentações que falaremos neste artigo.

Nessa parceria, buscávamos caminhos em que o enfrentamento dos acidentes de trabalho com perfurocortantes e outros problemas de saúde típicos do ambiente de trabalho hospitalar fosse feito coletivamente, de modo a produzir, no hospital, uma ampliação dos modos participativos de gestão do trabalho. Deu-se, então, o encontro entre experiências anteriores no campo nomeado "saúde do trabalhador" com a proposta teórico-metodológica da clínica da atividade (Clot, 2008; Osorio, \& Clot, 2010).

Essa experiência nos possibilita discutir a análise do trabalho como dispositivo clínico, ou seja, adequado para produzir um modo de intervenção que têm como objetivo ampliar a vitalidade dos coletivos de trabalho e de seus recursos para a ação. Expressa, portanto, um método de pesquisa que desafia o pensamento a superar o modelo da representação e considera que a produção de conhecimento sobre o trabalho se faz como um construtivismo (Wisner, 1995). Retomamos, aqui, a máxima segundo a qual é preciso transformar para conhecer, que implica intervenção no que está instituído na organização do trabalho em estabelecimentos e, no nosso caso, num hospital público no Rio de Janeiro/Brasil.

1 Universidade Federal Fluminense, em Niterói, Rio de Janeiro.
Destacamos, ainda, que, como estratégia metodológica, a pesquisa sofreu, ao longo do processo, reformulações, de forma a acompanhar os movimentos engendrados nas situações concretas vividas no campo. Entendemos que um pesquisador precisa lidar com um patrimônio constituído na história dos modos de fazer pesquisa, fazendo escolhas por direções e lidando com a emergência do singular, o que indica certa direção política da pesquisa.

Assumimos, então, a análise do trabalho no hospital como experiência e encontro, como uma clínica do trabalho.

\section{Elementos teóricos}

Na visada teórica da clínica da atividade, a compreensão da relação entre o trabalho e a subjetividade é centrada na atividade de trabalho como fonte permanente de recriação de formas de viver. A atividade e a subjetividade são motor e produto de um mesmo processo.

A atividade é sempre mais do que os gestos realizados, passíveis de observação direta. Sujeita a pressões, normas, situações mutantes, a atividade sempre se realiza em um plano de interferências de intenções, exigindo decisões do operador, que deve, então, proteger as suas de outras intenções concorrentes. Dizendo de outra forma, a atividade é sempre um conflito entre várias atividades possíveis. Sendo a atividade realizada uma ação estabelecida entre outras concorrentes, define-se a atividade de uma forma ampliada. Para além de uma concepção amorfa, desencarnada, da atividade de trabalho, propõe-se incluir nesse conceito os conflitos do real. A atividade não é somente aquilo que se faz. O real da atividade é também o que não se faz, o que não se pode fazer, o que se tenta fazer sem conseguir, o que se desejaria fazer, o que não se faz mais (Clot, 1999). Ou seja, as escolhas, as decisões a serem tomadas, as dúvidas, as alegrias e as insatisfações são parte do processo que é a atividade.

No trabalho se dá a construção coletiva de recursos para ação, constituindo-se o gênero da atividade de trabalho (Clot, 1999). O trabalhar é sempre coletivo, mesmo que se realize por um único trabalhador. Toda atividade de trabalho pode 
ser entendida como um encontro entre corpos, atravessamentos múltiplos que se agenciam, se interconectam, demandando escolhas e decisões e tornando todo trabalho uma atividade de criação. Mais do que um mero executor de tarefas, o trabalhador constitui sua atividade e é constituído por ela, sendo ao mesmo tempo produtor e produto, estando presente a capacidade de afetar e de ser afetado (Maia, 2006).

Esse referencial comum, pelo qual o gênero é constituído e do qual é constituinte, não deve ser entendido como o somatório dos referenciais individuais, como se ele fosse o todo e os indivíduos fossem as partes, pois ele possui um componente transpessoal, ou genérico, no sentido de que, sendo de todos, a ninguém pertence. $O$ gênero se constitui na dimensão transpessoal do ofício (Clot, 2006), daí sua dimensão coletiva. Esse referencial estabelece as regras não escritas e não imutáveis em uma situação dialógica que supõe a elaboração comum: "É necessário haver uma história comum de reorganização do trabalho coletivo para haver um coletivo de trabalho: a história aberta de uma estilização genérica indispensável para conservar uma capacidade de agir conjuntamente face ao real" (Clot, 2006, p. 128, tradução livre) ${ }^{2}$.

O gênero da atividade profissional pode ser definido como um instrumento para agir, um respondente profissional. É uma parte subentendida do trabalho que os trabalhadores daquele meio profissional conhecem, buscam e reconhecem, como um conjunto de regras sempre inacabadas, relativamente estabilizadas, que lhes é comum e que os reúne sob condições reais de vida; o que eles sabem que devem fazer, graças a uma comunidade de avaliações pressupostas, sem que seja necessário reespecificar a cada vez que a situação se apresenta (Clot, 2006, p. 129).

O gênero é permanentemente modificado pelos modos singulares como é tomado pelos trabalhadores. É objeto de renormatizações, de invenções que

2 [Il faut une histoire commune de réorganisation du travail collectif pour un collectif de travail: l'histoire ouverte d'une stylisation générique indispensable pour conserver une capacité d'agir ensemble face au réel]. se fazem a partir do gênero de atividade profissional, renovando esse mesmo gênero. $\mathrm{Na}$ atividade, os trabalhadores experimentam variantes dos modos habituais ou já consagrados de agir, ampliando, desse modo, os recursos coletivos para a ação.

Singular e coletivo ao mesmo tempo, o gênero é sempre plural, de forma que podemos entender que em toda atividade que se processa concorrem gêneros diferenciados, exigentes de um tempo diferente do prescrito para que possa haver a elaboração comum, só possível se privilegiarmos a formação de coletivos de trabalho. O tempo de produção, sem considerar o tempo necessário a essa elaboração comum, tão característico da organização do trabalho contemporâneo, em realidade impede de trabalhar, já que, na acepção da clínica da atividade, ter acesso ao gênero e ter o tempo necessário para dele se apropriar e para expandi-lo é fundamental para o processamento da atividade. Sem esse acesso a uma combinação de regras escritas e não escritas, torna-se difícil que o gênero exerça sua função de meio de ação, fazendo com que aqueles que trabalham estejam entregues a si mesmos em uma situação que se degrada, amputados em sua capacidade de agir, em sofrimento psíquico.

Se o debate entre os diferentes possíveis está dificultado, ou seja, se o gênero encontra-se em sofrimento, torna-se, então, difícil produzir sentido para a atividade, desenvolver-se pessoal e coletivamente. Quando o gênero não está disponível, em boas condições, decorre daí tanto um prejuízo para a saúde dos trabalhadores quanto para a segurança das operações e das instalações.

A análise do trabalho apresenta-se, então, como uma possibilidade de intervenção clínica, que tem como objetivo restabelecer o dinamismo do gênero. À clínica da atividade interessa compreender as relações entre o real e o realizado e as condições em que a experiência vivida pode ser, ou vir a ser, um meio de viver outras experiências. Com essa finalidade, estabelece-se que a atividade é a unidade de análise.

A análise da atividade se constitui em um diálogo que se estabelece entre o trabalhador e seu trabalho, entre vários trabalhadores, mas também entre o trabalhador e o pesquisador. E há ainda $\mathrm{o}$ 
diálogo do trabalhador consigo mesmo, um diálogo em que ele busca a melhor maneira de levar consigo o seu interlocutor, fazendo-o compreender seus modos de fazer. Nesse diálogo virtual, comparece o coletivo de ofício, que funciona como um diapasão que dá o tom daquilo que historicamente se estabeleceu como o modo genérico de funcionar do ofício em questão. O gênero da atividade profissional é um dos interlocutores da atividade dirigida, em que cada enunciado já é sempre uma reação a um enunciado anterior (Bakhtin, 2006).

É necessário considerar que o analista do trabalho é precedido, nesse meio, por aqueles que nele exercem seu ofício. Ele encontra aí sujeitos que já conhecem e interpretam seu meio ambiente de trabalho, tendo atribuído a esse trabalho sentidos que procuram preservar. Há aí

(...) uma psicologia prática construída pelos trabalhadores, exercida para decifrar os objetivos e os motivos das ações humanas, assim como para recriar os instrumentos diante dos caprichos do trabalho real. Essa psicologia é uma psicologia do sentido e da eficiência da ação ordinária. Por isso, comparada à psicologia científica, ela é, ao mesmo tempo, tão fortemente pessoal, coletiva, concreta e verdadeiramente viva. (Clot, 1999, p. 134, tradução livre) ${ }^{3}$

Encontramos, então, os conceitos cotidianos que organizam a experiência de trabalho implícitos nas descrições feitas pelos trabalhadores.

No processo de análise colocam-se em diálogo o saber da experiência e o saber acadêmico que é trazido pelo pesquisador, tomando como ponto de partida a experiência concreta do trabalho. Aqueles que têm sua atividade profissional posta em análise não transmitem aos pesquisadores verdades inquestionáveis sobre seu trabalho. Eles se servem da presença dos analistas para se confrontar com

$3[(. .$.$) une psychologie pratique construite par les travailleurs,$ exercée à décripter les buts et les mobiles des actions humaines aussi bien qu'à réconcevoir les instruments face aux caprices du travail réel. Cette psychologie est une psychologie du sens et de l'efficience de l'action ordinaire. C'est pourquoi, comparée à la psychologie scientifique, elle est à la fois si personnelle, si collective, si concrète et si véritablement vivante]. aspectos diversos de seu trabalho, com o que é possível e impossível. Assim, não só a atividade do trabalhador é analisada; a atividade do pesquisador também é indagada, e essa é uma manobra metodológica importante e imprescindível.

O diálogo que se dá como instância de desenvolvimento é alimentado por outros diálogos, anteriores e paralelos, existentes no grupo de trabalhadores, dos quais o grupo retoma temas a partir dos quais se produzem múltiplos eixos de análise. (Clot \& Faïta, 2000, p. 24).

Analisar os modos de fazer implica analisar as lutas que se dão para definir como cada objetivo será alcançado e, dentre vários objetivos concorrentes, qual será priorizado. A atividade de trabalho é um campo de conflito permanente. Para cada caminho escolhido existem muitos outros deixados de lado.

É em atividade que os meios para ação se desenvolvem, uma vez que analisar o trabalho é acompanhá-lo no seu movimento instituinte-criador. A análise da própria atividade é uma atividade sobre a atividade, em que se pode observar o processo de desenvolvimento e de ampliação do poder de agir do trabalhador sobre seu trabalho (Clot, 1999).

\section{Metodologia de pesquisa e intervenção}

\section{Metodologia na clínica da atividade}

O exercício de uma clínica da atividade supõe a instalação de um dispositivo desenvolvimental: a organização de uma nova atividade se superpõe à atividade ordinária que se busca transformar $\mathrm{e}$ compreender (Clot, 2004). Propõe-se nessa nova atividade uma forma de coanálise do trabalho, praticada no ambiente habitual de trabalho.

Dado que toda tentativa de compreender o trabalho é falha, sendo este sempre um processo em grande parte "invisível a olho nu", devemos pensar em empregar métodos para analisar a atividade que sejam também processuais, ou seja, que visem acompanhar processos, e não representar uma realidade dada. Segundo Vigotski (2007), é em movimento que um corpo mostra o que é. Assim, é pela experimentação transformadora que a atividade de trabalho pode mostrar seus segredos (Clot, 
2004), “já que é transformando cada 'realização’ em recurso para uma nova 'realização' que o real da atividade se manifesta em seus desenvolvimentos"4 (Clot citado por Litim, 2006, p. 91, tradução livre). É nessa perspectiva que Yves Clot e Daniel Faïta (2000) propuseram o método das autoconfrontações cruzadas.

No método da autoconfrontação cruzada, são feitas filmagens em vídeo de dois trabalhadores que realizam uma mesma tarefa, escolhida de forma coletiva em discussões entre os pesquisadores e o grupo de referência, ou seja, o grupo de trabalhadores que acompanha a pesquisa. Em um primeiro momento faz-se uma autoconfrontação simples, em que cada trabalhador comenta as sequências filmadas em vídeo de sua própria atividade. Esses comentários são dirigidos ao pesquisador. No segundo momento, configurando a autoconfrontação cruzada, cada trabalhador produz um novo comentário, das mesmas sequências filmadas, agora dirigido não apenas ao pesquisador, mas também ao colega (o outro trabalhador filmado). Os comentários dirigidos ao pesquisador e ao par, colega da mesma profissão, não serão os mesmos.

Nesse processo, há uma atividade de análise, feita tanto sobre a atividade filmada quanto sobre a atividade de pesquisa. Essa análise é voltada para seu objeto — os registros em vídeo —, mas também para o pesquisador e para o colega. $O$ sujeito busca no psicólogo e no colega pistas de como agir sobre seus interlocutores, tornando-os receptivos a seus argumentos. Como falar de seu trabalho ao pesquisador? E como fazê-lo ao se dirigir ao colega? Ele não busca diretamente em si mesmo, nos seus próprios conhecimentos, mas no outro. Desse modo, ele verá sua própria atividade pelos olhos de outros. E encontrará algo novo, sem que tenha necessariamente procurado (Clot, 2004).

Em nossa experiência, propusemos, seguindo a mesma metodologia, outro método: registrar a atividade em fotos.

$4 \quad[(\ldots)$ car c'est $(\ldots)$ en transformant chaque 'réalisation' en ressource pour une nouvelle 'réalisation' que le réel de l'activité se manifeste dans ses développements].
Inicialmente escolhemos a fotografia como meio de registro por questões de viabilidade técnica. Em primeiro lugar, a filmagem em vídeo exigiria da equipe de pesquisa recursos de filmagem e de edição de que não dispúnhamos. Em segundo lugar, a realização da análise na autoconfrontação cruzada se dá em um espaço de tempo ${ }^{5}$ não compatível com o período de formação de alunos de psicologia e residentes de saúde pública - e essa formação era um dos objetivos de nossa colaboração com o hospital. Necessitávamos, portanto, de outro método.

Fazer as fotos é uma atividade sobre sua atividade cotidiana, é produzir novas realidades (Maurente \& Titonni, 2007). Observamos, então, que seria possível levar os próprios trabalhadores a fazerem as fotos a serem analisadas: a máquina fotográfica poderia produzir um efeito interessante, de distanciamento e de produção de espaço para o diálogo interior, ou seja, para um diálogo consigo e com o gênero profissional em questão.

Essas mesmas marcas da atividade - fotos são foco de uma nova atividade: a discussão com pares e pesquisadores, devendo o fotógrafo dizer por que as fez da forma como fez.

\section{A máquina fotográfica e a fotografiah}

Nas oficinas de fotos as imagens são produzidas pelos próprios trabalhadores. Pretende-se, assim, ampliar a participação direta dos trabalhadores no processo de pesquisa. Eles são chamados a inventar os seus caminhos sem ter de tudo explicitar aos pesquisadores.

O trabalhador assume, empunhando a máquina fotográfica, o protagonismo no trabalho de análise: ele dirige a produção das imagens. Na situação aqui apresentada, as fotos foram feitas com uma única máquina para um pequeno grupo. Assim, vários debates entre pares são necessários desde essa etapa, para decidir o que e como fotografar.

5 De acordo com o que é apresentado em reuniões de pesquisa da Equipe de Clínica da Atividade (CNAM-Paris), as intervenções que utilizam o método da autoconfrontação cruzada duram, na maioria dos casos, cerca de 18 meses. 
$\mathrm{Na}$ tomada das fotos existem diálogos reais e virtuais em curso. $\mathrm{O}$ diálogo interior provocado pela observação inicial do pesquisador se reativa, mediado pela máquina fotográfica. No momento seguinte, em que as fotos produzidas são exibidas ao pesquisador e aos pares, uma nova etapa de observação e de diálogo real e virtual entra em cena.

Aspectos que não passaram pelo crivo do pensamento participam da confecção da foto. Mesmo a si mesmo, nem tudo é explicitado. Olhar a situação de trabalho fotografada, aquela situação na qual corriqueiramente ele se desembaraça de obstáculos sobre os quais nem chega a comentar consigo ou com pares, provoca algo novo. Nas oficinas realizadas, esse olhar as fotos se dá em grupos. Então, quando a foto produzida é apresentada aos demais participantes da oficina, aos pares e ao pesquisador, surgem comentários que são suscitados ali mesmo, sutilezas, paradoxos, complexidades do trabalho que vão se sucedendo no foco de atenção do autor inicial da foto e do grupo que a analisa.

Temos também observado que a fotografia porta na atualidade características de algo lúdico e muito familiar. A foto digital, que pode ser produzida por máquinas simples e telefones celulares, tornou a atividade de registrar momentos interessantes de sua vida algo a que muitos têm acesso. A proposta de fazer um trabalho conjunto mediado pela fotografia opera uma transformação na relação pesquisador-pesquisado. A proposta clara da ação a ser partilhada - fotografar aspectos do seu cotidiano de trabalho e comentá-los - tem suscitado imediato interesse em diferentes ambientes de trabalho.

\section{O método da oficina de fotos}

A primeira oficina de fotos foi realizada numa manhã, das 8 às 12 horas, e foi seguida de uma reunião de restituição, de uma hora de duração, realizada após quatro semanas.

Foi proposto aos participantes da oficina que produzissem fotos de situações que eles considerassem como produtoras da saúde do trabalhador da área da saúde e fotos de situações que, sempre de seu próprio ponto de vista, pudessem ser prejudiciais para a manutenção da saúde desse profissional.
Nas oficinas foram usadas máquinas fotográficas digitais. Em um grupo de 12 profissionais participantes, foram organizados quatro subgrupos, cada um portando uma máquina e acompanhado de um monitor encarregado de dar suporte à tarefa, sem interferir na escolha dos temas. Antes de se encaminhar a seus setores de trabalho, o subgrupo discutiu o que ia fotografar. Dirigiu-se ao local escolhido tendo um tempo definido para o retorno.

Para definir para onde dirigir a objetiva, fez-se necessário um primeiro debate entre pares. Eram três pessoas, com uma única máquina fotográfica, que tinham como tarefa fotografar situações em que poderiam aparecer objetos, mas também outros trabalhadores do hospital, pacientes ou familiares de pacientes.

Nesse momento, como nos seguintes, se deram diálogos reais e virtuais. Estes, os virtuais, talvez viessem a se tornar audíveis na discussão em que entrariam outros interlocutores, que não compartilhavam do mesmo gênero de atividade profissional: os componentes da Comissão de Saúde do Trabalhador e os coordenadores da oficina - no caso, pesquisadores/ psicólogos e alunos ligados ao curso de psicologia.

Cada subgrupo tinha a tarefa de mostrar ao grupo maior cinco fotos de situações propiciadoras de saúde e cinco de situações que poderiam produzir desgaste. Os subgrupos retornaram com muitas fotos e fizeram então uma seleção. As fotos selecionadas pelos quatro subgrupos foram exibidas com o auxílio de data show e discutidas uma a uma. Ao final foram selecionadas, dentre as 40 fotos discutidas, dez fotos para compor um pôster a ser apresentado na Assembleia Científica anual do hospital. Nesse pôster, os participantes da oficina figuraram como fotógrafos. A partir de então, outras oficinas de fotos foram realizadas com pequenas variações na sua dinâmica, buscando sempre desenvolver a proposta metodológica da clínica da atividade.

Após essa primeira experiência, outras foram realizadas, tanto no âmbito dos serviços de saúde (Martins, 2012) quanto em outros, como educação (Rosemberg, Ronchi Filho, \& Barros, 2011) e organizações de outros setores (Pacheco, Barros, \& Osorio, 2012). Nessas pesquisas-intervenções, a metodologia da clínica da atividade se mantém, 
bem como o método que toma a fotografia como mediador importante dos diálogos. Não há um protocolo fixo, mas variações em que essas permanências nos autorizam a nomeá-las oficinas de fotos.

A intervenção em clínica da atividade - e, de modo específico, o método da oficina de fotos busca mais que analisar as formas de dominação e sofrimento existentes: busca provocar as possibilidades que os trabalhadores têm de criar e recriar recursos para sua atividade profissional. $\mathrm{O}$ dispositivo instalado deve levar o trabalhador à posição de observador de seu próprio trabalho. $\mathrm{O}$ analista do trabalho, como interlocutor, busca possibilitar que o trabalhador se surpreenda com aquilo que, por muito familiar, já passa despercebido. E favorecer que os diferentes modos possíveis de enfrentamento do real da atividade sejam postos em debate, desenvolvendo o gênero e ampliando suas possibilidades como instrumento para a ação de cada um.

No método por nós nomeado oficina de fotos, as várias etapas da tarefa proposta exigem dos participantes pôr o trabalho de todo dia em debate. Modos diferentes de fazer e pensar o trabalho vêm à baila quando se tem como tarefa coletiva definir o que fotografar, o que não fotografar, como fotografar as situações escolhidas, o que e como apresentar para o debate com um grupo maior. Esse debate se dá inicialmente num grupo restrito de pares, na presença de um monitor. Amplia-se, a princípio, com interlocutores virtuais: deve-se definir o que será apresentado ao grupo maior e ao analista do trabalho que coordena a oficina. Prossegue com a definição do que e de como apresentar ao hospital, por meio de um pôster para a Semana Científica: o que se deseja pôr em debate com as hierarquias, com um público amplo de pares e visitantes, como amostra da atividade realizada, suas características e suas dificuldades? Com esse instrumento, o ofício fala, diálogos diversos são entabulados em diferentes planos que se cruzam.

\section{Resultados e análise}

Tomando como exemplo a primeira experiência, realizada em um hospital, é possível observar algumas características do trabalho que faz sentido para enfermeiras, técnicas e auxiliares de enfermagem do hospital.

Em várias fotos ${ }^{6}$ apareceu o trabalho realizado em meio a relações de colaboração, principalmente interprofissional; por exemplo, o momento em que uma médica e uma enfermeira trabalham juntas em uma bancada.

A organização, ou a ordem, é tida pelos profissionais de enfermagem como facilitadora do trabatho bem-feito, sendo algo que favorece a saúde do trabalhador da área da saúde. Essa característica do gênero da atividade profissional foi trazida à oficina com a foto de um almoxarifado do centro cirúrgico, bem equipado e com os materiais perfeitamente organizados em uma grande estante.

Já a desorganização foi apontada como algo que agride a saúde desse trabalhador. Essa afirmativa surgiu com fotos em que bancadas de trabalho estão ocupadas com materiais diversos, em uma (falta de) organização que impede seu uso. $\mathrm{Ou}$, mais grave, em que a caixa de descarte de materiais perfurocortantes já utilizados (infectados) está colocada por trás de outras coisas, impedindo o descarte seguro.

Assim, muitas situações que são relacionadas à melhor qualidade da atenção prestada ao doente são apontadas como positivas para a saúde do trabalhador da assistência. Essa é uma afirmativa interessante, dado que fala de um valor importante para o trabalhador - o valor do trabalho bem-feito (Clot, 2008) - para que possa haver satisfação no trabalho e promoção da saúde do próprio trabalhador. Em diferentes fotos e comentários, esse valor foi reafirmado pelos trabalhadores de enfermagem desse hospital público como de grande importância.

Surgem também como elementos positivos: a possibilidade de desfrutar de momentos de pausa e descanso; a capela do hospital, como local de recolhimento; a árvore florida no pátio interno; e a linda vista que se tem de algumas janelas do hospital.

As fotos e suas análises trazem ao debate a complexidade do trabalho. A mesma foto do pátio interno do hospital, com lindas flores, apresenta ao

6 Um relato mais detalhado dessa experiência, com algumas fotos, foi publicado em 2010 na Revista Informática na Educação: teoria e prática (Osorio, 2010). 
fundo as rampas construídas para um possível escape de emergência. Mas não estão bem conservadas, lembram os participantes, e estão escorregadias.

As polêmicas comparecem também no que diz respeito ao trabalho em equipe. Se todos concordam que essa colaboração é positiva, os modos de ver as relações de hierarquia não são consensuais: algumas enfermeiras participantes consideram a hierarquia importante, necessária, enquanto outras defendem a construção de relações mais horizontais.

A controvérsia também está presente na discussão da presença de acompanhantes, em geral familiares, junto ao doente internado. Uma foto de uma criança acompanhada por sua avó foi tirada por enfermeiras que consideram essa presença positiva, mas muitos participantes trouxeram para o debate as dificuldades existentes no manejo da situação.

Após o evento científico em que o pôster foi exibido, foi feita uma reunião de restituição. Nesta foram relatados outros diálogos sobre o trabalho que teriam sido disparados pela oficina ou pela exibição do pôster. Foi relatado também que, ao saber que alguns setores de trabalho dispunham de salas de descanso, outras equipes que não dispõem desses espaços em seus setores de trabalho estavam se mobilizando para produzir para si mesmas algo similar.

Nessa primeira experiência foi possível verificar a potência do método da oficina de fotos. As indicações metodológicas da clínica da atividade são aí desenvolvidas levando aos efeitos desejados: produção de diálogos que permitem melhor conhecer recursos para a ação próprios desse ofício e do gênero (local) de atividade profissional, pôr em debate valores e modelos em que a polêmica existe e deve ser desenvolvida, bem como produzir afetos que levam à modificação objetiva de algumas condições de trabalho.

As demais experiências, a que nos referimos brevemente, também têm levado a resultados encorajadores.

\section{Conclusão}

$\mathrm{Na}$ oficina de fotos, usando a máquina fotográfica como instrumento, desloca-se o trabalhador para o lugar de observador e analista do seu trabalho. Também o analista/pesquisador do trabalho é ins- trumento do debate sobre o trabalho que se instala, já que um novo interlocutor também induz o mesmo deslocamento.

Nessa situação clínica, o debate se faz sobre uma marca do trabalho: uma marca produzida coletivamente, já como fruto do diálogo que põe o gênero em manutenção. Desse modo, o debate se faz sobre a atividade, evitando a personalização e o julgamento sobre as escolhas individuais. As polêmicas suscitadas são trazidas sem que se considere que há necessariamente uma verdade, ou que o consenso seja o objetivo. Ao contrário, a controvérsia é aceita como um recurso para ampliação de recursos coletivos para a ação.

O dispositivo fotografia, utilizado para análise do trabalho no hospital, foi, reafirmamos, engendrado a partir das situações concretas, tendo como objetivo a interferência nas "práticas naturalizadas", pois entendemos que os dispositivos se articulam às realidades singulares de trabalho, comportam diferentes vetores e múltiplos tensionadores, sendo experimentados e avaliados de acordo com valores que emergem nas situações de trabalho, e não em modos de fazer universais e abstratos de análise. Um dispositivo não se sustenta, portanto, sem essa torção do olhar do "universal, eterno e imutável" para a criação de (outros) possíveis, partindo da experiência daqueles que trabalham. Esse olhar crítico para o processo perspectiva a ampliação das possibilidades de intervenção nos modos como o trabalho está organizado.

Assim foi tomado o dispositivo fotografia na experiência no hospital: sustentado por posturas críticas, que produzem crise, que nascem nas experiências, em composição com uma metodologia aberta, que vislumbra reorganizar processos e resultados, e não engessada em metas descoladas do que se faz em situação de trabalho. Tal dispositivo vislumbrou criar, coletivamente, condições efetivas de modos de gerir-cuidar.

Por último, mas não menos importante, o debate se faz de modo recorrente, favorecendo deslocamentos, elaborações e reelaborações nas análises que se produzem.

No momento atual observamos, na maior parte dos locais de trabalho, gêneros fragilizados com re- 
cursos precários de que os trabalhadores necessitam para o enfrentamento dos dilemas da atividade. Aumentam as exigências e reduzem-se os recursos existentes para fazer frente a essas exigências. Nessa situação, os coletivos de trabalho enfraquecidos encontram dificuldades em fazer a necessária manutenção dos recursos para a ação que compõem os gêneros de atividade profissional a que nos referimos. A atividade clínica em psicologia do trabalho é demandada de diversas formas. Esse é, então, o gênero de atividade profissional que cabe a nós desenvolver: uma psicologia do trabalho clínica, que já vem sendo proposta por outros autores - como Ivar Oddone (Oddone \& Briante, 1981), na Itália _, mas que carece ser desenvolvida.

E, retomando o que foi apresentado inicialmente, o desenvolvimento, no Brasil, de uma rede de vigilância em saúde do trabalhador coloca para os profissionais da área da saúde de diferentes inserções uma convocação à qual devemos responder. $\mathrm{E}$ responder contribuindo para um gênero "saúde do trabalhador" em que se destaquem seus eixos mais libertários, e não aqueles mais ligados a propostas de controle e disciplinamento.

Com esse objetivo, entendemos que uma dimensão da tarefa de análise do trabalho é a própria construção do espaço de análise, tomando o plano de produção dos serviços e dos sujeitos como estratégico, uma vez que com a clínica da atividade se busca intervir-transformar e acompanhar um processo, e não descrever ou representar a realidade de um ou outro serviço, categoria profissional ou posto de trabalho.

Associada a essa dimensão da tarefa de análise se articula uma aposta: a de entender que, numa dinâmica transversal, analisar o trabalho é explorar e desestabilizar os modos instituídos de trabalhar e potencializar forças instituintes que compõem uma determinada situação, interferindo vivamente naquela realidade e engendrando outras que viabilizam a ampliação do poder de agir dos trabalhadores. Essa aposta inclui a necessária interlocução com outras experimentações e metodologias de pesquisa comprometidas com essa dimensão epistemológica e política, afirmando autonomia e protagonismo dos trabalhadores.

\section{Referências}

Bakhtin, M. (2006). Adendo: os gêneros do discurso. In Estética da Criação Verbal (pp. 261-306). São Paulo: Martins Fontes.

Clot, Y. (1999). La fonction psychologique du travail. Paris : PUF.

Clot, Y. (2004). Le travail entre fonctionnement et développement. Bulletin de Psychologie, 57(1), 5-12.

Clot, Y. (2006). Lactivité entre l'individuel et le collectif: approche développementale. In G. Vallery \& R. Amalberti (Orgs.), Lanalyse du travail en perspective: influences et évolutions (pp. 127-139). Toulouse : Octarès.

Clot, Y. (2008). Travail et pouvoir d'agir. Paris : PUF.

Clot, Y., \& Faïta, D. (2000). Genres et styles en analyse du travail : concepts et méthodes. Travailler, 4, 7-42.

Litim, M. (2006). Les histoires du travail: un instrument $d u$ développement du métier et de l'activité professionnelle. Une analyse de l'activité soignante en gérontologie. Tese de Doutorado nao publicada, Conservatoire des arts et métiers, Paris, France.

Maia, M. A. B. (2006). O corpo invisivel do trabalho: cartografia dos processos de trabalho em saúde. Dissertação de Mestrado não publicada, Programa de Pós-Graduação em Psicologia da Universidade Federal Fluminense, Niterói, Brasil.

Martins, L. R. A. (2012). Um estudo sobre a atividade das pessoas com transtornos mentais graves, em oficinas terapêuticas: atividade como construção de saúde. Dissertação de Mestrado não publicada, Programa de Pós-Graduação em Psicologia da Universidade Federal Fluminense, Niterói, Brasil.

Maurente, V., \& Tittoni, J. (2007). Imagens como estratégia metodológica em pesquisa: a fotocomposição e outros caminhos possíveis. Psicologia e Sociedade, 19(3), 33-38.

Oddone, I., \& Briante, G. (1981). Redécouvrir l'expérience ouvrière : vers une autre psychologie du travail? Paris: Messidor/Editions Sociales.

Osorio, C. (2010). Experimentando a fotografia como ferramenta de análise da atividade de trabalho. Revista Informática na Educação: Teoria e Prática, 13(1), 41-49.

Osorio, C., \& Clot, Y. (2010). Lanalyse collective des accidents du travail : une méthode d'analyse pour 
intégrer la dimension subjective et développer le genre professionnel. Activités, 7(1), 28-41.

Osorio da Silva, C., \& Oliveira, N. (1999). Intervenções em saúde do trabalhador: psicólogos numa Comissão de Saúde do Trabalhador num Hospital Geral Público no Rio de Janeiro. Revista do Departamento de Psicologia - UFF, 11(1), 40-50.

Pacheco, A., Barros, M. E. B., \& Osório da Silva, C. (2012). Trabalhar o mármore e o granito: entre cores e ritmos. Cadernos de Psicologia Social do Trabalho, 15(2), 255-270.

Rosemberg, D. S., Ronchi Filho, J., \& Barros, M. E. B. (Orgs.). (2011). Trabalho docente e poder de agir: clínica da atividade, devires e análises. Vitória: EDUFES.

Vigotski, L. S. (2007). A formação social da mente. São Paulo: Martins Fontes.

Wisner, A. (1995). Réflexions sur l'ergonomie. Toulouse: Octarès. 